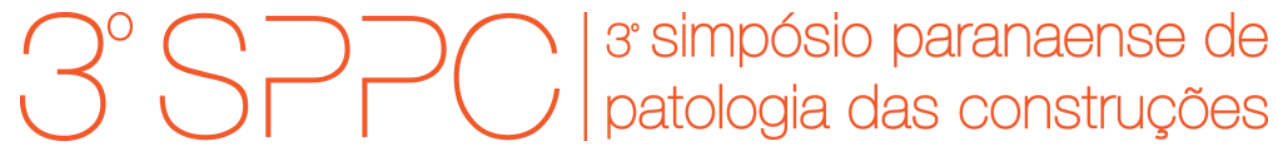

ISSN 2526-7248 artigo n. 3SPPC1019, pp. 209-219, 2018

\title{
Estudo da influência de agregado reciclado de concreto em argamassa de cal
}

Silva, Tharlyana Tharcia Rodrigues ${ }^{1}$; Nascimento, Nicole Pamela da Silva ${ }^{2}$; Nascimento, Carlos Fernando Gomes ${ }^{3}$; Silva, Thaís Marques ${ }^{4}$; Câmara, Felipe Figueirôa de Lima ${ }^{5}$; Costa e Silva, Ângelo Just da ${ }^{6}$;

${ }^{1}$ Engenheira Civil, Universidade Católica de Pernambuco,tharlyana@gmail.com

${ }^{2}$ Mestranda, Universidade Católica de Pernambuco, nicolenascimentoeng@gmail.com

${ }^{3}$ Graduando, Universidade Católica de Pernambuco, carlosfernando.gn@gmail.com

${ }^{4}$ Mestranda, Universidade de Pernambuco, thaism21@ymail.com

${ }^{5}$ Engenheiro Civil, Universidade Católica de Pernambuco, eng2.felipe@gmail.com

${ }^{6}$ Professor, Universidade de Pernambuco e Universidade Católica de Pernambuco, angelo@tecomat.com.br

Resumo: Diversos problemas socioeconômicos giram em torno da indústria da construção civil, o que vem provocando mudanças significativas em suas atividades. $O$ consumo exacerbado de matéria prima e sua relação com a sustentabilidade é motivo de preocupação para muitas áreas, principalmente para a indústria da construção civil. A busca por meios mais sustentáveis para reduzir os impactos é de responsabilidade de todos. Dentre tantos resíduos provenientes da construção civil podemos citar o resíduo de concreto pré-moldado (resíduo cinza), como um que possui grande potencial para a utilização na construção civil. Esta pesquisa traz um estudo do desempenho mecânico de argamassa à base de cal. Foram realizadas substituições, parcial e total, do agregado miúdo natural pelo resíduo cinza de concreto. A partir dos principais fatores envolvidos na aderência da argamassa e na análise dos resultados foram desenvolvidos os ensaios propostos em laboratórios especializados. Através do ensaio de resistência à compressão foi constatado que houve um ganho de $5 \%$ quando ocorreu a substituição total do agregado natural pelo agregado reciclado.

Palavras-chave: Argamassa, Resistência da Argamassa, Resíduo Cinza, Agregado Reciclado, Sustentabilidade.

Abstract: Several socioeconomic problems revolve around the construction industry, which has been causing significant changes in its activities. The exacerbated consumption of raw material and its relation with sustainability is cause for concern in many areas, especially for the construction industry. The search for more sustainable ways to reduce impacts is everyone's responsibility. Among so many waste from the construction industry we can mention the precast concrete residue (gray waste), as one that has great potential for use. This research brings a study of the mechanical performance of lime based mortar. Partial and total substitutions of the natural small aggregate by the gray concrete residue were performed. From the main factors involved in the adhesion of the mortar and in the analysis of the results the tests proposed in specialized laboratories were developed. Through the compressive strength test, it was verified that there was a gain of $5 \%$ when the total replacement of the natural aggregate by the recycled aggregate occurred.

Keywords: Mortar, Mortar Strength, Gray Waste, Recycled Aggregate, Sustainability. 


\section{Introdução}

Atualmente a construção civil é um dos grandes geradores da economia mundial, elevando a capacidade de desenvolvimento dos países. Fatores como este estimulam o interesse na descoberta de novas tecnologias e de novos materiais, buscando a utilização de materiais reciclados em substituição dos materiais naturais. Com o desenvolvimento do setor da construção, cresce proporcionalmente o uso de materiais como o concreto, provocando grandes impactos ao meio ambiente.

A construção sustentável vem se baseando em ações que visam a diminuição de resíduos gerados desde a fase de projetos até a fase da execução adequada com materiais ecologicamente corretos.

Este estudo permitirá o aumento dos conhecimentos acerca das argamassas de revestimento, constatando através de análises experimentais o comportamento de quatro famílias de diferentes proporções de cal e cimento variando o agregado miúdo.

\section{Revisão Bibliográfica}

\subsection{Argamassa de Revestimento}

Argamassa é um material de construção com propriedades de aderência e endurecimento, obtidos a partir da mistura homogênea de um ou mais aglomerantes, agregado miúdo e água, podendo conter aditivos e adições mineiras, com 0 intuito de melhorar determinadas propriedades da mistura (Carasek, 2010 [1]). Segundo o Manual de Revestimento de Argamassas da Associação Brasileira de Cimento Portland (ABCP, 2002 [2]), os componentes das argamassas são: Cimento Portland, Cal Hidratada, agregado miúdo (areia), água e algum aditivos que em alguns casos são adicionados à mistura com a finalidade de melhorar as propriedades da argamassa no estado fresco e endurecido.

\subsubsection{Funções}

As argamassas de revestimento devem cumprir importantes funções, sendo utilizadas primordialmente para impermeabilizar o substrato de aplicação, garantir um bom acabamento ao revestimento, absorver as deformações naturais, regularizar e/ou proteger mecanicamente o substrato.

Além dessas, existem as conferidas quando empregadas em assentamentos, são elas: unir solidariamente entre si os elementos que compõe a alvenaria, garantir adesão ao substrato, distribuir uniformemente os esforços atuantes em uma alvenaria, garantindo a impermeabilização das alvenarias. Para a argamassa cumprir as funções relacionadas é necessário apresentar algumas propriedades como: trabalhabilidade, capacidade de retenção de água, durabilidade, estabilidade química, física e módulo de elasticidade.

\subsubsection{Características e Propriedades}


As argamassas de revestimento se enquadram em características específicas para se adequar as suas funções tanto no estado fresco como no estado endurecido. A conduta da argamassa é modificada com a alteração das proporções de seus materiais constituintes, podendo variar sua qualidade. Esse comportamento tem influência no desenvolvimento das propriedades do revestimento.A propriedade é tão importante quando observada logo após a aplicação como também na manutenção da propriedade ao longo do tempo.

Alguns fatores como condições climáticas (temperatura, UR e vento), porosidade e rogosidade do substrato bem como o modo de execução, limpeza e cura, podem influênciar negativamente na aderência da argamassa com o substrato. A diminuição da resistência de aderência pode ser causada também por fadiga da ligação da argamassa com a base. O uso da cal hidratada ou de aditivos de base polimérica podem reduzir a falta de aderência.

\subsection{Cal Hidratada em Argamassa de Revestimento}

De acordo com (Paiva et.al. 2007 [3]), a qualidade da cal está relacionada ao seu processo de fabricação desde o controle de qualidade do minério até a forma de hidratação. A obtenção da cal de maneira natural não tem controle de tamanho, temperatura de calcinação, volume de água, entre outros cuidados, podendo originar uma cal com cristais insolúveis, produzidos com altas temperaturas, ou cristais com o seu núcleo carbonatado por falta de calor, além de partículas com tamanhos irregulares, produzidas pela má trituração.

\subsubsection{Cal Hidratada}

Com base em (Aragão, 2012 [4]), a cal é um aglomerante aéreo de origem mineral proveniente do calcário. O calcário, depois de extraído, selecionado e moído, é submetido a altas temperaturas em fornos industriais para o processo de calcinação, que origina o $\mathrm{CaO}$ e $\mathrm{CO} 2$.

Conforme as especificações da NBR 11172 (ABNT, 1990 [5]), a cal hidratada é obtida pela hidratação adequada da cal virgem, composta essencialmente de $\mathrm{Ca}(\mathrm{OH}) 2$ ou de uma mistura desse com $\mathrm{Mg}(\mathrm{OH}) 2$ ou ainda, de uma mistura de $\mathrm{Ca}(\mathrm{OH}) 2, \mathrm{Mg}(\mathrm{OH}) 2$ e $\mathrm{MgO}$.

A cal virgem se transforma em cal hidratada pelo contato com o ar úmido, ou através de hidratadores. A hidratação da cal é uma reação exotérmica, provoca altos índices de calor, também é a mais conhecida e estudada pela propriedade aglomerante que reflete às argamassas. A capacidade aglomerante é quantitativa pelo teor dos hidróxidos presentes no produto. Os carbonatos residuais constituemse na fração inerte da cal.

\subsubsection{Classificação da Cal Hidratada}

A cal hidratada pode ser classificada em três tipos: $\mathrm{CH}$ I, $\mathrm{CH}$ II e $\mathrm{CH}$ III. Todos os tipos são submetidos aos mesmos ensaios nas mesmas exigências de resultados. 
$\mathrm{CH}$ I: constituída essencialmente de hidróxido de cálcio, ou da mistura de hidróxido de cálcio e hidróxido de magnésio, e possui um ter de gás carbônico menor ou igual a $5 \%$;

$\mathrm{CH}$ II: constituída de uma mistura de hidróxido de cálcio, hidróxido de magnésio e óxido de magnésio, com teor de gás carbônico menor ou igual a $5 \%$ e sem limites para os teores de óxidos não hidratados;

CH III: constituída da mistura de hidróxido de cálcio, hidróxido de magnésio e óxido de magnésio, e conter um teor de gás carbônico menor ou igual que $13 \%$.

\subsubsection{Propriedades}

A utilização da cal traz grandes benefícios para a construção como: permitir a extensão da aderência, desacelerar o tempo de pega mantendo a argamassa elástica e restabelecer algumas fissuras.

De acordo com (Costa e Silva, 2015 [6]), a cal é um material que em mistura com a água forma pasta com propriedades aglutinantes e com baixa resistência, quando submetida à ação da água. Também consegue manter a água na mistura, retardando a secagem por evaporação ou sucção da base.

\subsection{Agredado Reciclado de Concreto}

A NBR 15116 (ABNT, 2004 [7]) define resíduo de construção civil como sendo um material obtido através de processos de reciclagem de rejeitos provenientes de construção, reformas, reparos e demolições de obras. É também proveniente do resultado da preparação e da escavação de terrenos, como: tijolos, blocos cerâmicos, concreto, solo, rocha, madeira, forros, argamassa, gesso, telha, pavimento asfáltico, vidro, plástico, tubulações, entre outros.

O agregado reciclado é um material granular proveniente do beneficiamento de resíduos de construção civil, que apresenta características técnicas para a aplicação em obras de edificações e infraestrutura. São caracterizados pela alta absorção de água e perda das propriedades mecânicas, quando comparados aos agregados naturais.

A classificação dos Resíduos da Construção Civil no Brasil se dá pela Resolução CONAMA 307 (2002) Art. $3^{\circ}$, que define como Classe A todos os resíduos reutilizáveis e reciclaveis como agregados, tais como os resíduos de construção, demolição, reforma e reparos de pavimentação e de edificações bem como os resíduos de processos de fabricação e/ou demolição de peças pré-moldadas em concreto.

Quando o agregado reciclado é proveniente de resíduos da construção civil, pode ser classificado em dois grupos:

- Agregado Reciclado de Concreto (ARC): é obtido pela reciclagem de concreto fresco ou endurecido, com fração graúda de no mínimo $90 \%$ da massa de fragmentos a base de cimento Portland e rochas que devem 
atender aos parâmetros para aplicações específicas da norma NBR 15116 (ABNT, 2004 [8]);

- Agregado de Resíduo Misto (ARM): obtido de acordo com o item de agregados reciclados de concreto, constituído na sua fração graúda por menos de $90 \%$ em massa de fragmento a base de cimento Portland e rochas que também devem atender aos parâmetros de aplicação da NBR 15116 (ABNT, 2004 [9]).

A utilização de agregados reciclados visa à diminuição dos resíduos gerados pela construção civil e do aproveitamento como material de construção, reduzindo também o consumo de matéria prima.

\section{Planejamento experimental}

A finalidade desta pesquisa foi de analisar o comportamento da argamassa de cal quando substituido o agregado miúdo natural pelo agregado reciclado nas porcentagens de $50 \%$ e $100 \%$. Os traços utilizados para a análise são apresentados em massa na Tabela 01.

Tabela 01: Traços realizados. (Autor, 2017)

\begin{tabular}{|c|c|c|c|c|}
\hline FAMÍLIAS & CIMENTO & CAL & $\begin{array}{c}\text { AGREGADO } \\
\text { RECICLADO }\end{array}$ & $\begin{array}{c}\text { AGREGADO } \\
\text { NATURAL }\end{array}$ \\
\hline F1 & - & 1 & - & 3 \\
\hline F2 & - & 1 & 1,5 & 1,5 \\
\hline F3 & - & 1 & 3 & - \\
\hline
\end{tabular}

\subsection{Materiais utilizados}

Na realização deste projeto foram utilizados os seguintes materiais:

- Cal hidratada $\mathrm{CH} 1$;

- Agregado miúdo: areia natural, coletada na Região Metropolitana do Recife RMR isento de impurezas e umidade;

- Agregado miúdo Reciclado: resíduo de concreto coletado de uma empresa de fabricação de blocos pré-moldados de concreto na Região Metropolitana do Recife - RMR. Os blocos que seriam descartados por problemas na qualidade, foram levados para trituração em uma empresa que trabalha com reaproveitamento de materiais da construção civil;

- Água: utilizada da rede pública da Companhia Pernambucana de Saneamento (COMPESA), considerada potável, ressaltando a ausência de ensaios para sua caracterização.

\subsubsection{Granulometria}


O ensaio de granulometria foi realizado segundo a NBR NM 248:2003. Os resultados obtidos estão descritos nas Tabelas 02 e 03. As Fig. 01 e 02 mostram as curvas granulométricas de cada um dos agregados utilizados, a partir dos resultados obtidos.

\begin{tabular}{c|c|c|c}
\hline PENEIRA (mm) & $\begin{array}{c}\text { MASSA RETIDA } \\
(\mathbf{g})\end{array}$ & $\begin{array}{c}\text { \% MASSA } \\
\text { RETIDA }\end{array}$ & $\begin{array}{c}\% \\
\text { ACUMULADA }\end{array}$ \\
\hline 6,30 & 2,20 & 0,73 & 0,73 \\
4,80 & 1,00 & 0,33 & 1,07 \\
2,40 & 7,30 & 2,43 & 3,50 \\
1,20 & 33,90 & 11,30 & 14,80 \\
0,60 & 71,50 & 23,83 & 38,63 \\
0,30 & 118,70 & 39,57 & 78,20 \\
0,15 & 44,10 & 14,70 & 92,90 \\
\hline FUNDO & 19,10 & 6,37 & 99,27 \\
\hline TOTAL & 298,80 & 99,60 \\
\hline DMC & \multicolumn{3}{|c}{$2,4 \mathrm{~mm}$} \\
\hline MF & 2,31 \\
\hline
\end{tabular}

Tabela 2: Granulometria do agregado natural

\begin{tabular}{c|c|c|c}
\hline PENEIRA (mm) & $\begin{array}{c}\text { MASSA RETIDA } \\
\mathbf{( g )}\end{array}$ & $\begin{array}{c}\text { \% MASSA } \\
\text { RETIDA }\end{array}$ & $\begin{array}{c}\text { \% } \\
\text { ACUMULADA }\end{array}$ \\
\hline 6,30 & 1,20 & 0,40 & 0,40 \\
4,80 & 3,70 & 1,23 & 1,63 \\
2,40 & 67,70 & 22,57 & 24,20 \\
1,20 & 66,00 & 22,00 & 46,20 \\
0,60 & 108,40 & 36,13 & 82,33 \\
0,30 & 51,90 & 17,30 & 99,63 \\
0,15 & 0,00 & 0,00 & 99,63 \\
\hline FUNDO & 0,00 & 0,00 & 99,63 \\
\hline TOTAL & 298,90 & 99,63 \\
\hline DMC & \multicolumn{3}{|c}{$4,8 \mathrm{~mm}$} \\
\hline MF & 3,55 \\
\hline
\end{tabular}

Tabela 3: Granulometria do agregado reciclado 


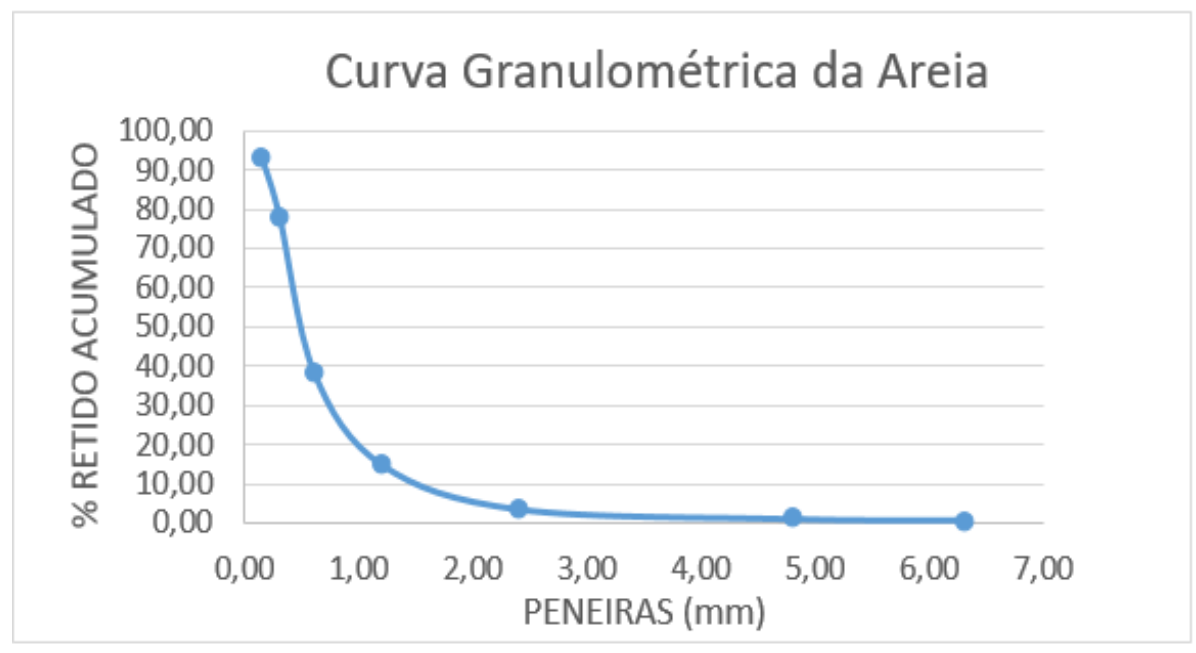

Figura 1: Curva Granulométrica do agregado natural

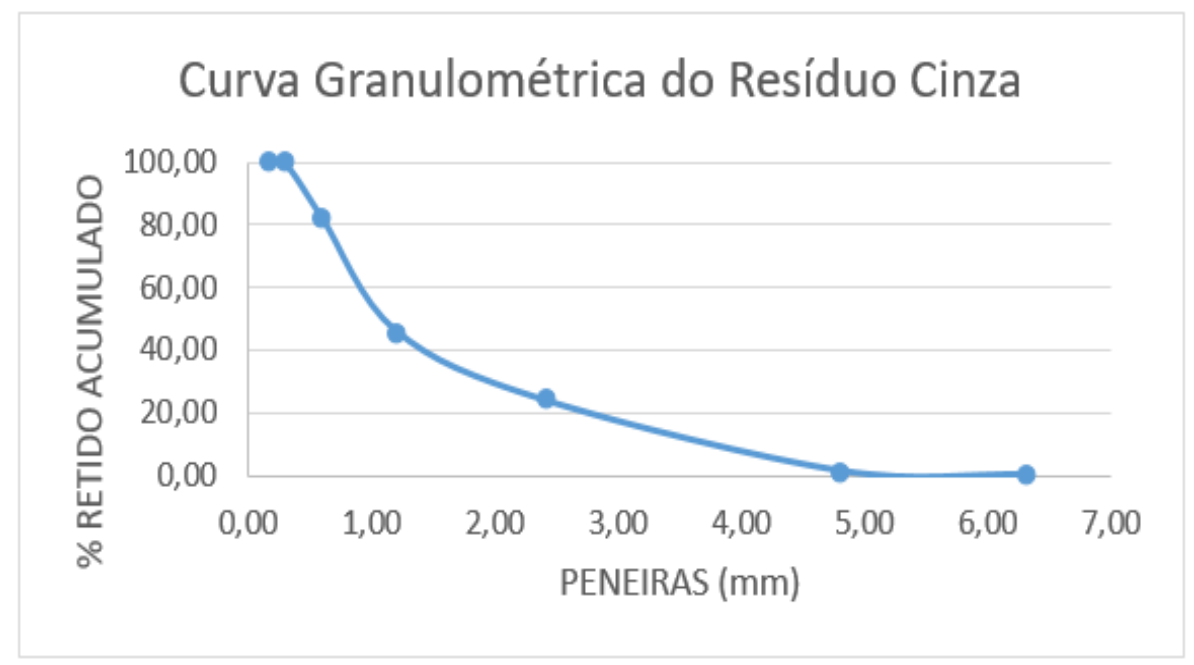

Figura 2: Curva Granulométrica do Resíduo Cinza

\subsubsection{Determinação do Índice de Consistência}

A finalidade da determinação do índice de consistência da argamassa é de caracterizar a quantidade de água a ser utilizada nos traços propostos.

Este ensaio segue as orientações da NBR 16541 (ABNT, 2016 [10]) e da NBR 13276 (ABNT, 2016 [11]). Segundo as normas citadas o procedimento do preparo da argamassa necessita da dosagem de 2,5kg de materiais secos, com aproximação de $1 \mathrm{~g}$, para cada família.

A escolha da relação água/aglomerante foi de $450 \mathrm{ml}$ de água, aproximadamente 0,72 a relação água/aglomerante.

Aicionou-se toda a mistura na cuba da argamassadeira em velocidade baixa, acrescentando $75 \%$ da água, por 30 segundos desde a adição da massa no misturador. Ao fim dos primeiros 30 segundos altera-se para velocidade alta por mais 60 segundos; somando 90 segundos à argamassadeira é desligada e com o 
auxílio de uma espátula raspou-se toda a mistura, homogeneizando, por mais 90 segundos.

Passados os 90 segundos de repouso, a cuba é recolocada no misturador, em velocidade baixa, e foi adicionado os $25 \%$ restantes de água e continuou a misturar por mais 30 segundos.

Para a determinação do índice de consistência, foi realizado o ensaio "flow table". Iniciou-se com a limpeza do tampo da mesa e da parede do molde troncônico com um pano umedecido. O molde foi centralizado à mesa e deu-se início a adição da mistura de argamassa. Foram colocadas três camadas com alturas aproximadamente idênticas e foram golpeadas cada camada, respectivamente, com quinze, dez e cinco golpes com o soquete, de forma a serem distribuídas semelhantemente.

Em sequência foi retirado o molde verticalmente, provocando o derramamento da argamassa sobre a mesa. Imediatamente foram operadas 30 rotações na manivela do equipamento, de modo que a mesa subisse e caísse uma vez a cada segundo. $\mathrm{Na}$ continuidade foi feita a medição do diâmetro com o auxílio do paquímetro, medindo em 3 direções diferentes para obter 3 dimensões. Foi requerido um diâmetro ideal de $260 \pm 35 \mathrm{~mm}$. Repetiu-se o mesmo procedimento para todas as famílias.

Adotados todos os índices de consistências das quatro famílias, foram realizados alguns experimentos. Para cada família foram preparados 3 corpos-de-prova prismáticos de dimensão $4 \mathrm{~cm} \times 4 \mathrm{~cm} \times 16 \mathrm{~cm}$. As moldagens foram realizadas de acordo com a NBR 13279 (ABNT, 2005 [12]) e a seguir foi realizado o adensamento.

Repetiu-se o mesmo procedimento para todas as famílias, Os resultados dos diâmetros medidos foram demonstrados na Tabela 05 juntamente com a média.

Tabela 05: Resultados dos índices de Consistência. (Autor, 2017)

\begin{tabular}{c|c|c|c}
\hline \multicolumn{4}{c}{ RESULTADOS (mm) } \\
\hline MEDIDAS & $\begin{array}{c}\text { F1 - 450ml de } \\
\text { água }\end{array}$ & $\begin{array}{c}\text { F2 - 500ml de } \\
\text { água }\end{array}$ & $\begin{array}{c}\text { F3 - 450ml de } \\
\text { água }\end{array}$ \\
\hline $1^{\text {a }}$ & 255 & 294 & 265 \\
$2^{\text {a }}$ & 262 & 295 & 273 \\
$3^{\text {a }}$ & 266 & 296 & 273 \\
\hline MÉDIA & $\mathbf{2 6 1}$ & $\mathbf{2 9 5}$ & $\mathbf{2 7 0 , 3 3}$ \\
\hline
\end{tabular}

\section{Resultados}

Para alcançar os resultados foram realizados ensaios de resistência à tração na flexão e à compressão. Os procedimentos de ruptura dos corpos-de-prova seguiram as recomendações da NBR 13279 (ABNT, 2005), que determina a ruptura na idade de 28 dias. 
No ensaio de resistência à tração na flexão, o corpo-de-prova foi posicionado no dispositivo de apoio do equipamento, de modo que a face não fique em contato com os dispositivos de apoio nem com o dispositivo da carga. Sendo aplicada uma carga de $50 \pm 10 \mathrm{~N} / \mathrm{s}$ até a ruptura. Os resultados do ensaio de resistência á tração na flexão estão dispostos na Tabela 06. A Fig. 04 representa um gráfico desses resultados.

Tabela 06: Resultados de ensaio a tração na flexão. (Autor, 2017)

\begin{tabular}{r|c|c|c}
\hline \multicolumn{4}{c}{ RELATÓRIO DE ENSAIO - TRAÇÃO NA FLEXÃO } \\
\hline FAMÍLIAS & F1 & F2 & F3 \\
\hline CP1 & 1,01 & 0,91 & 0,71 \\
CP2 & 0,95 & 0,90 & 0,70 \\
CP3 & - & 0,88 & - \\
\hline MÉDIAS & $\mathbf{0 , 9 8 0}$ & $\mathbf{0 , 8 9 7}$ & $\mathbf{0 , 7 0 5}$ \\
\hline DESVIO PADRÃO & $\mathbf{0 , 0 4 2}$ & $\mathbf{0 , 0 1 5}$ & $\mathbf{0 , 0 0 7}$ \\
\hline CV (\%) & $\mathbf{4 , 3 2 9}$ & $\mathbf{1 , 7 0 4}$ & $\mathbf{1 , 0 0 3}$ \\
\hline
\end{tabular}

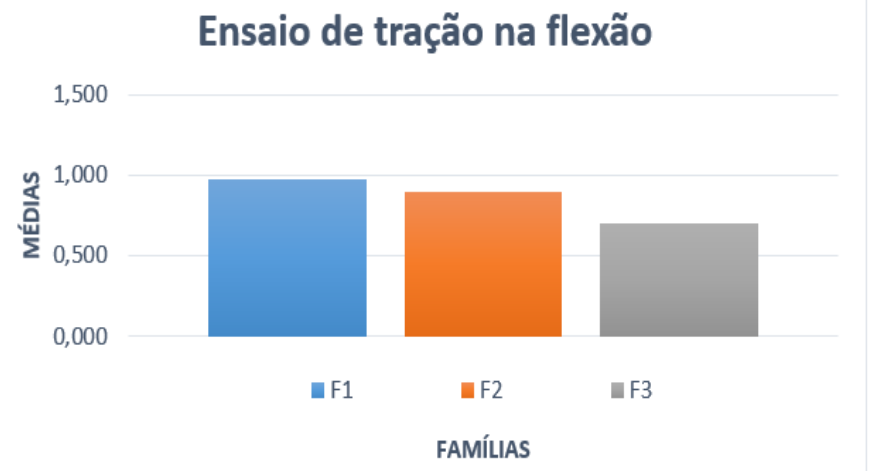

Figura 03: Gráfico do resultado do ensaio de tração. (Autor, 2017)

Foi observado que a substituição total do agregado natural pelo agregado reciclado não favorece a argamassa, pois há uma queda significativa na sua resistência à tração em $3 \%$. Também não apresenta ganho quando substituído parcialmente em relação a família 1. Pode-se destacar que esses resultados deram menor devido a diversos fatores, tais como: a forma de execução do experimento, a moldagem e a dosagem.

O procedimento experimental para determinar resistência a compressão utilizou-se as metades dos corpos-de-prova, provenientes do ensaio de tração na flexão. Posicionando cada parte no dispositivo de apoio do equipamento de ensaio. A carga aplicada é de $500 \pm 50 \mathrm{~N} / \mathrm{s}$ até a ruptura. Os resultados foram medidos diretamente pelo computador do laboratório para a composição da Tabela 07 e os gráficos na Fig. 04.

A argamassa com substituição total do agregado miúdo, obtêm um aumento de $5 \%$ em sua resistência a compressão, quando comparada com a família 1 . A família 2 apresenta o menor índice de variância, porém não apresenta uma resistência satisfatória. A diminuição da resistência pode ter ocorrido pela alteração da relação de água/aglomerante, aproximadamente 0,8 , entre diversos fatores. 
Tabela 07: Resultados do ensaio de conpressão

\begin{tabular}{|c|c|c|c|}
\hline \multicolumn{4}{|c|}{ RELATÓRIO DE ENSAIO - COMPRESSÃO NA F' rv ñ } \\
\hline FAMÍLIAS & F1 & F2 & F3 \\
\hline \multirow{2}{*}{ Fck 1} & 1,5 & 1,4 & 1,7 \\
\hline & 1,7 & 1,3 & 1,6 \\
\hline \multirow{2}{*}{ Fck 2} & 1,3 & 1,3 & 1,4 \\
\hline & 1,4 & 1,3 & 1,6 \\
\hline \multirow{2}{*}{ Fck 3} & 1,5 & 1,3 & 1,6 \\
\hline & 1,5 & 1,4 & 1,5 \\
\hline MÉDIAS & 1,483 & 1,333 & 1,567 \\
\hline DESVIO PADRÃO & 0,133 & 0,052 & 0,103 \\
\hline CV (\%) & 8,961 & 3,873 & 6,592 \\
\hline
\end{tabular}

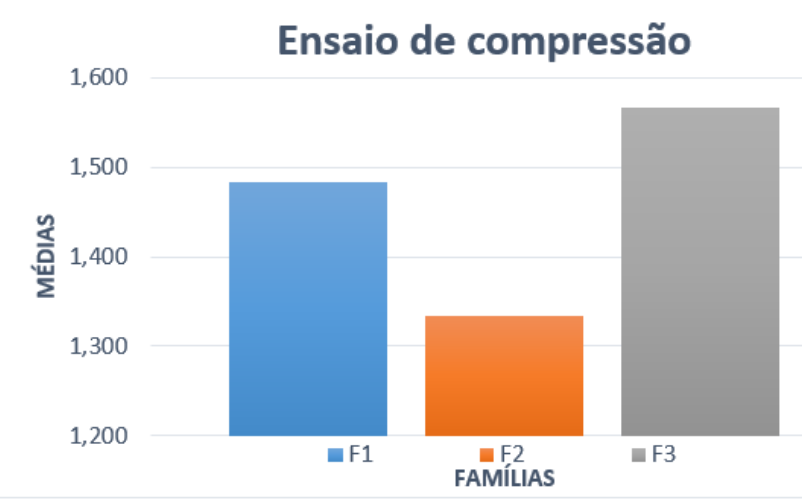

Figura 04: Gráfico de resultados do ensaio de compressão

\section{Considerações finais}

A elaboração deste estudo proporcionou uma avaliação quanto ao comportamento de uma argamassa de revestimento com diferentes famílias à base de cal hidratada.

Após o levantamento de todos os dados e resultados, foi possível a percepção que vários objetivos propostos foram, de fato, alcançados, comprovando que a adição de resíduo cinza, em certos casos, nas argamassas de cal é possível para a melhoria da resistência à compressão.

Este estudo conclui que a reutilização do resíduo cinza é vantajosa e possível em certos aspectos. Possivelmente a realização de mais experimentos, com um número maior de corpos-de-prova e ensaios, deverá subsidiar outras pesquisas, sendo melhorar os resultados. Os valores encontrados são referentes a esta pesquisa, pois, para o uso, se faz necessário o aperfeiçoamento das técnicas utilizadas.

\section{Agradecimentos}

O desenvolvimento deste artigo é de grande relevância para a comunidade acadêmica e não seria possível sem a colaboração de todos os participantes. Agradecemos a todos os envolvidos direta e indiretamente, em especial ao Profo ${ }^{\circ}$ Dr $^{-}$ Ângelo Just da Costa e Silva e à Universidade Católica de Pernambuco. 
SILVA, T. T. R. et al., ESTUDO DA INFLUÊNCIA DE AGREGADO RECICLADO DE CONCRETO EM ARMAGAMASSA DE CAL. $3^{\circ}$

\section{Referências}

[1] CARASEK, Helena. Materiais da construção civil e princípios de ciência e engenharia de matérias, editor: Geraldo C. Isaia. 2 ed. São Paulo, IBRACON, 2010.

[2] ASSOCIAÇÃO BRASILEIRA DE CIMENTO PORTLAND (ABCP), Manual de Revestimento de Argamassas, 2002. Disponível em: http://www.comunidadedaconstrucao.com.br/upload/ativos/279/anexo/ativosman u.pdf Acesso em: 6 de novembro de 2017

[3] PAIVA, Sérgio Carvalho. Controle de qualidade da cal para argamassas metodologias alternativas. Revista Ciências e Tecnologia Disponível em: http://www.unicap.br/revistas/revista_e/artigo8.pdf Acesso em: 9 de novembro de 2017.

[4] ARAGÃO, Maj Moriz. A cal - Aglomerante. Disponível em: http://transportes.ime.eb.br/ moniz/matconst2/cal.pdf Acesso em: 9 de novembro de 2017.

[5] ASSOCIAÇÃO BRASILEIRA DE NORMAS TÉCNICAS (ABNT), NBR 11172: Aglomerantes de origem mineral. Rio de Janeiro, 1990.

[6] COSTA E SILVA, Angelo. Cal e suas aplicações em argamassas. Disponível em:http://www.tecomat.com.br/angelo/arquivos/Cal\%20e\%20suas\%20aplicacoe s.pdf Acesso em: 9 de novembro de 2017.

[7] ASSOCIAÇÃO BRASILEIRA DE NORMAS TÉCNICAS (ABNT), NBR 15116: Agregado reciclado de resíduos sólidos da construção civil - Utilização em pavimentação e preparo de concreto sem função estrutural. Rio de Janeiro, 2004.

[8] ASSOCIAÇÃO BRASILEIRA DE NORMAS TÉCNICAS (ABNT), NBR 15116: Agregado reciclado de resíduos sólidos da construção civil - Utilização em pavimentação e preparo de concreto sem função estrutural. Rio de Janeiro, 2004.

[9] ASSOCIAÇÃO BRASILEIRA DE NORMAS TÉCNICAS (ABNT), NBR 15116: Agregado reciclado de resíduos sólidos da construção civil - Utilização em pavimentação e preparo de concreto sem função estrutural. Rio de Janeiro, 2004.

[10]ASSOCIAÇÃO BRASILEIRA DE NORMAS TÉCNICAS (ABNT), NBR 16541: Argamassas para assentamento e revestimento de paredes e tetos - Preparo da mistura para a realização de ensaios. Rio de Janeiro, 2016.

[11]ASSOCIAÇÃO BRASILEIRA DE NORMAS TÉCNICAS (ABNT), NBR 13276: Argamassas para assentamento e revestimento de paredes e tetos - Preparo da mistura e determinação do índice de consistência. Rio de Janeiro, 2002.

[12]ASSOCIAÇÃO BRASILEIRA DE NORMAS TÉCNICAS (ABNT), NBR 13279: Argamassas para assentamento e revestimento de paredes e tetos Determinação da resistência à tração na flexão e à compressão. Rio de Janeiro, 2005. 